\title{
Factors driving the use of dermoscopy in Europe: a pan-European survey
}

\author{
A.M. Forsea, ${ }^{1}$ P. Tschandl, ${ }^{2}$ V. del Marmol, ${ }^{3}$ I. Zalaudek, ${ }^{4}$ H.P. Soyer, ${ }^{5}$ Eurodermoscopy Working Group, \\ A.C. Geller, ${ }^{6}$ and G. Argenziano ${ }^{7}$ \\ ${ }^{1}$ Dermatology Department, Elias University Hospital, Carol Davila University of Medicine and Pharmacy, Bucharest, Romania \\ ${ }^{2}$ Department of Dermatology, Medical University of Vienna, Vienna, Austria \\ ${ }^{3}$ Dermatology Department, Universite Libre de Bruxelles, Hopital Erasme, Brussels, Belgium \\ ${ }^{4}$ Department of Dermatology and Venereology, Non-Melanoma Skin Cancer Unit, Medical University of Graz, Graz, Austria \\ ${ }^{5}$ Dermatology Research Centre, The University of Queensland, School of Medicine, Translational Research Institute, Brisbane, Australia \\ ${ }^{6}$ Social and Behavioral Sciences, Harvard T.H. Chan School of Public Health, Boston, MA, U.S.A. \\ ${ }^{7}$ Dermatology Unit, Second University of Naples, Naples, Italy
}

\section{Summary}

\section{Correspondence \\ Ana-Maria Forsea. \\ E-mail: aforsea@yahoo.com. \\ Accepted for publication \\ 20 July 2016}

\section{Funding sources}

The web-based platform for online surveys used by the study was made available unconditionally by the International Dermoscopy Society.

\section{Conflicts of interest}

None declared.

A.M.F. and P.T. contributed equally to this work.

The members of the Eurodermoscopy Working Group are listed in the Appendix.

DOI $10.1111 /$ bjd. 14895
Background When used correctly, dermoscopy is an essential tool for helping clinicians in the diagnosis of skin diseases and the early detection of skin cancers. Despite its proven benefits, there is a lack of data about how European dermatologists use dermoscopy in everyday practice.

Objectives To identify the motivations, obstacles and modifiable factors influencing the use of dermoscopy in daily dermatology practice across Europe.

Methods All registered dermatologists in 32 European countries were invited to complete an online survey of 20 questions regarding demographic and practice characteristics, dermoscopy training and self-confidence in dermoscopic skills, patterns of dermoscopy use, reasons for not using dermoscopy and attitudes relating to dermoscopy utility.

Results We collected 7480 valid answers, of which $89 \%$ reported use of dermoscopy. The main reasons for not using dermoscopy were lack of equipment (58\% of nonusers) and lack of training (42\%). Dermoscopy training during residency was reported by $41 \%$ of dermoscopy users and by $12 \%$ of nonusers $(\mathrm{P}<0.001)$. Dermatologists working in public hospitals were the least likely to use dermoscopy. High use of dermoscopy across the spectrum of skin diseases was reported by $62 \%$ of dermoscopy users and was associated with dermoscopy training during residency, the use of polarized light and digital dermoscopy devices, longer dermoscopy practice, younger age and female gender.

Conclusions Expanding access to dermoscopy equipment, especially in public healthcare facilities and establishing dermoscopy training during dermatology residency would further enhance the substantially high dermoscopy use across European countries.

\section{What's already known about this topic?}

- Dermoscopy is a well-established tool for the noninvasive diagnosis of skin diseases.

- The benefits of dermoscopy depend on correct use by trained physicians.

- Although considered to be widely used in Europe, reports on dermoscopy use by dermatologists have been carried out in only two European countries so far.

\section{What does this study add?}

- Our study is the first pan-European survey of dermatologists regarding the patterns of use, training and attitudes towards dermoscopy. 
- We report on the demographic, practice- and training-related factors driving or hampering the use of dermoscopy in the daily practice of dermatologists in 32 European countries.

Dermoscopy has become an essential tool for the early detection of skin cancers and noninvasive dermatological diagnosis. ${ }^{1,2}$ It is considered to be widely used in Europe; however, reports on dermoscopy use by dermatologists have been carried out in only two European countries so far, ${ }^{3-5}$ compared with broader analysis in Australia ${ }^{6,7}$ and the U.S.A. ${ }^{8-11}$

While skin cancer incidence continues to rise, important differences in skin cancer burden have been reported across Europe, ${ }^{12-15}$ with late diagnosis, underdiagnosis and poorer prognosis reported in many Central and Eastern European countries. ${ }^{12,16}$ Moreover, it is estimated that half of the worldwide melanoma deaths occur in European countries. Dermoscopy, as an established, easy-to-use and accessible technique of in vivo skin visualization, may contribute towards improving early detection of skin cancers and alleviating these disparities.

Dermoscopy has evidence-confirmed benefits for increasing the accuracy of skin cancer diagnosis. It increases clinicians' accuracy in melanoma detection ${ }^{1,17-19}$ and can reduce the number of unnecessary biopsies of benign lesions. ${ }^{20-23}$ Dermoscopy also supports the in vivo differentiation of a wide range of pigmented and nonpigmented skin tumours, ${ }^{24,25}$ and its role in distinguishing neoplastic from inflammatory lesions is expanding. ${ }^{26-28}$ Consequently, dermoscopy is considered the standard of care for skin cancer diagnosis and monitoring of high-risk groups and is included in the current clinical practice guidelines worldwide. ${ }^{29-32}$ Yet its benefits depend on correct use by experienced and trained physicians. ${ }^{18}$ Thus, it is important to understand the patterns of dermoscopy use across Europe, the obstacles to its optimal use and the pathways by which this technique could be made available for a wider proportion of European dermatologists in order to enhance the noninvasive diagnosis of skin diseases.

Towards this goal, we conducted the first pan-European analysis of the use of dermoscopy by dermatologists, seeking information on the motivations, barriers and modifiable factors related to the use of dermoscopy in the daily practice across the continent.

\section{Materials and methods}

The study consisted of a survey of European dermatologists, conducted under the auspices of the International Dermoscopy Society (IDS).

\section{Study instrument}

The study questionnaire was developed by the study's task force experts (G.A., A.M.F., H.P.S., I.Z., A.C.G. and V.M.), in agreement with the IDS guidelines and literature-reported practices. $^{5,7}$ The questionnaire comprised a core of 20 multiple-choice questions (Appendix S1; see Supporting Information) regarding demographic and practice characteristics, dermoscopy training and use patterns, opinions about dermoscopy utility and self-reported confidence in dermoscopic diagnosis. The questionnaire excluded personal identification questions and was translated into the languages of all participant countries.

\section{Study participants}

The study was intended for all licensed dermatologists registered in European countries defined by the United Nations Organization classification. ${ }^{33}$ In each participating country, a National Coordinating Team (NCT), led by a National Coordinator $(\mathrm{NC})$, took the responsibility of implementing the study, collaborating with national dermatology and dermoscopy professional associations. NCs were members of the IDS Board of Directors, or Country Coordinators of the Euromelanoma campaign $^{34}$ for the countries without an IDS Board representative. The responsibilities of the NCs included accessing the national databases of dermatologists, obtaining the necessary study approvals at national level, communicating the number of dermatologists officially registered in the country, survey translation, survey dissemination solely to registered dermatologists nationwide, motivating dermatologists to participate, collecting offline responses and participating in the reporting of study results.

\section{Participating countries}

A total of 39 countries in the Europe region ${ }^{33}$ were invited to participate and three additional countries (Turkey, Israel and Georgia) joined the study as part of the Council of Europe. ${ }^{35}$ An effective National Coordination was established in 33 countries; one country (Ukraine) could not complete the study owing to political instability. A total of 32 countries completed the study and data from the following countries are included in the present analysis: Austria, Belgium, Belarus, Bosnia-Herzegovina, Bulgaria, Czech Republic, Croatia, Estonia, France, Germany, Georgia, Greece, Hungary, Ireland, Israel, Italy, Latvia, Lithuania, the former Yugoslav Republic of Macedonia, Norway, the Netherlands, Portugal, Romania, Russia, Serbia, Slovenia, Slovak Republic, Spain, Sweden, Switzerland, Turkey and the U.K.

\section{Survey dissemination}

Survey dissemination occurred through the IDS web-based platform for online surveys. For each participating country a dedicated webspace was created, accessible by a 
country-specific link and containing the electronic survey translated in the country's language. The country access link was communicated by each NC to all registered dermatologists in the respective national database. NCTs had the option to use additional offline methods for survey dissemination (post, e-mail, etc.) fulfilling the study criteria, i.e. anonymity, restriction to nationally registered dermatologists and avoidance of duplicate responses. Slovenia and Lithuania conducted the survey offline only. Offline data were introduced manually into electronic databases using Microsoft Excel (Microsoft Corporation, Redmond, WA, U.S.A.) by the respective NCTs, verified by a study task force member and merged with the central study database.

\section{Survey collection}

Dermatologists in each country used the country-specific link to access the online questionnaire and were instructed to complete the survey only once. The survey was anonymous and only responders answering 'yes' to Question 9 ('Do you use dermoscopy?') could proceed to later questions regarding the practice of dermoscopy use. The IDS online survey platform was open between 1 July 2014 and 1 December 2014, during which period NCTs sent four reminders to all dermatologists in their contact databases. Online responses were collected in an access-restricted central database, grouped by country access code. They were subsequently merged with the electronic databases of offline responses transmitted by the NCTs.

\section{Data processing}

Data cleaning of the study database was performed by three independent investigators (A.M.F., P.T. and G.G.) who eliminated empty entries, duplicate entries (same IP address, sex, age, practice settings), technical error entries and invalid answers defined as missing or unrealistic answers in any of Questions 1-8.

\section{Statistical analysis}

Answers to Questions 1-18 are analysed in the present work. Continuous data are given as mean and SD unless stated otherwise, and parametric tests for comparing groups were used only if corresponding assumptions were met. Comparing proportions of two groups $\chi^{2}$-test and comparing proportions of ordered groups $\chi^{2}$-test for trends in proportions were used. For multivariate analysis all variables that were significant in the univariate analysis were entered using a model with backwards elimination, controlled for sex, age, years in practice and numbers of patients with skin cancer and overall number of patients seen per month. Remaining predictors are given as odds ratios with 95\% confidence intervals. Questions regarding confidence in using dermoscopy and advantages of dermoscopy were rated on a 3-point Likert scale. To differentiate 'high' dermoscopy users from 'low' dermoscopy users, a score was created by summarizing levels of percentages of indicated use in the three categories of inflammatory, pigmented and nonpigmented skin lesions (Question 15), where a score of between 1 and 5 points could be obtained in every category. The summarized score could range from 3 to 15 points, and was separated into two groups ('high' and 'low' users) by kmeans clustering. Those who reached the cut-off of 11 points were classified as 'high users' who used dermoscopy in at least two application fields more than $50 \%$ of the time.

A $P<0.05$ was regarded as statistically significant; in univariate analysis P-values were adjusted using the method described by Holm. ${ }^{36}$ All statistical computation and generation of graphics were performed using $\mathrm{R}$ (https://www. r-project.org) with the packages ggplot $2^{37}$ and Likert (https://cran.r-project.org/package=likert).

\section{Results}

The study included 32 European countries, in which a total number of 38300 dermatologists were registered by the relevant national health authorities, as reported by the NCTs. A total of 8297 online responses and 222 offline responses were collected. The response rate, defined as the proportion of respondents divided by the total number of certified dermatologists in each country, ranged from $7 \%$ to $69 \cdot 7 \%$ and had a median value of $33.2 \%$ for all participating countries. After data cleaning, a total of 7480 valid responses were maintained for analysis.

\section{Factors associated with use of dermoscopy by European dermatologists}

The majority of respondents were women (69\%), and the mean age was 46.7 years. Overall, $89 \%$ of respondents reported using dermoscopy, with a slightly lower proportion of women in the dermoscopy users group (68\% vs. $79 \%$, $\mathrm{P}<0.001)$. In the univariate analysis and multivariate analysis, using dermoscopy was significantly associated with the following: working in a private individual practice or in a university hospital, involvement in teaching activities, higher number of patients and higher number of patients with skin cancer seen monthly (Table 1). Dermoscopy users reported having received dermoscopy training during residency more frequently than nonusers of dermoscopy (41\% vs. $12 \%$, $\mathrm{P}<0.001)$ and also having received any type of other dermoscopy training. Almost $50 \%$ of nonusers reported that they had not received any type of dermoscopy training. Working in public healthcare facilities was associated with a lower rate of dermoscopy use.

\section{Reasons for not using dermoscopy}

Among the 822 dermatologists not using dermoscopy, the main reasons for not using this technique were the lack of equipment (not available or too expensive) and a lack of education (no dermoscopy training or not being confident in their own dermoscopy skills) (Fig. 1). Cost played a lesser 
1332 Factors driving the use of dermoscopy in Europe, A.M. Forsea et al.

Table 1 Factors associated with the use of dermoscopy

\begin{tabular}{|c|c|c|c|c|}
\hline & Dermoscopy users & Nonusers & P-value & $\begin{array}{l}\text { P-value } \\
{\text { (multivariate })^{\mathrm{a}}}\end{array}$ \\
\hline$N=7424$ & $6602(88.92)$ & $822(11 \cdot 08)$ & & \\
\hline Female participants & $4442(67 \cdot 66)$ & $643(78 \cdot 8)$ & $<0.001$ & $0 \cdot 001$ \\
\hline Age, years, mean (SD) & $46 \cdot 95(11.01)$ & $43 \cdot 7(11.96)$ & $<0.001$ & \\
\hline \multicolumn{5}{|l|}{ Place of work } \\
\hline Individual private practice & $2517(38 \cdot 12)$ & $141(17 \cdot 15)$ & $<0.001$ & 0.001 \\
\hline Private ambulatory/hospital & $1340(20 \cdot 30)$ & $205(24 \cdot 94)$ & $0 \cdot 060$ & \\
\hline Public ambulatory/hospital & $2026(30 \cdot 69)$ & $440(53.53)$ & $<0.001$ & $<0.001$ \\
\hline University hospital & $1387(21 \cdot 01)$ & $78(9 \cdot 49)$ & $<0.001$ & $0 \cdot 011$ \\
\hline $\begin{array}{l}\text { Involved in teaching activity for } \\
\text { dermatology residents }\end{array}$ & $844(12 \cdot 78)$ & $71(8 \cdot 64)$ & 0.021 & \\
\hline $\begin{array}{l}\text { No. of years as a dermatologist, } \\
\text { mean (SD) }\end{array}$ & $16 \cdot 17(10 \cdot 72)$ & $14.92(10.98)$ & 0.063 & \\
\hline $\begin{array}{l}\text { No. of patients seen per month, } \\
\text { mean (SD) }\end{array}$ & $433 \cdot 21(405 \cdot 58)$ & $275 \cdot 91(294 \cdot 29)$ & $<0.001$ & $<0.001$ \\
\hline $\begin{array}{l}\text { No. of patients with skin cancer } \\
\text { seen per month, mean (SD) }\end{array}$ & $58 \cdot 65(107 \cdot 11)$ & $8 \cdot 85(39 \cdot 33)$ & $<0.001$ & $<0.001$ \\
\hline Dermoscopy training during residency & $2709(41 \cdot 64)$ & $97(12 \cdot 02)$ & $<0.001$ & $<0.001$ \\
\hline \multicolumn{5}{|c|}{ Types of dermoscopy training outside of residency } \\
\hline Dermoscopy course & $4162(63 \cdot 04)$ & $120(14 \cdot 60)$ & $<0.001$ & $<0.001$ \\
\hline Online dermoscopy course & $1202(18 \cdot 21)$ & $41(4 \cdot 99)$ & $<0.001$ & $<0.001$ \\
\hline Attended conferences congresses & $4721(71 \cdot 51)$ & $213(25 \cdot 91)$ & $<0.001$ & $<0.001$ \\
\hline Books and atlases & $5289(80 \cdot 11)$ & $268(32 \cdot 60)$ & $<0.001$ & $<0.001$ \\
\hline Mentor tutor & $1537(23 \cdot 28)$ & $58(7 \cdot 06)$ & $<0.001$ & $<0.001$ \\
\hline No training & $220(3 \cdot 33)$ & $395(48.05)$ & $<0.001$ & $<0.001$ \\
\hline
\end{tabular}

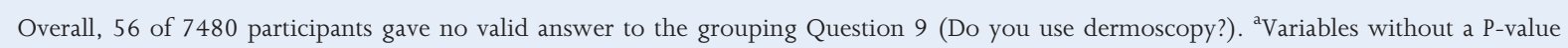
in this column were not significant in multivariate analysis and were not entered to the model as they did not improve the regression model. Continuous data are given as mean with SD, proportions as $\mathrm{n}(\%)$.

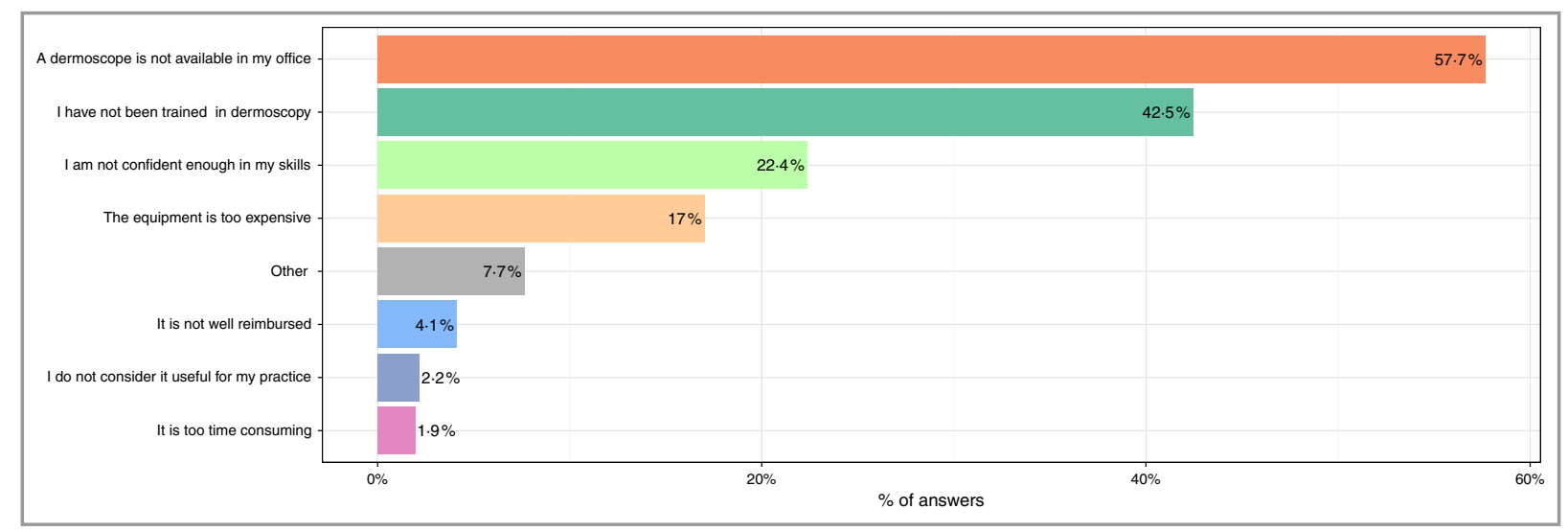

Fig 1. Reasons for not using dermoscopy reported by European dermatologists.

role $(17 \%)$ and reimbursement did not appear to be important. The vast majority of those not using dermoscopy (98\%) still regarded it as a useful technique.

When the results were stratified by practice setting, the most common reason for not using dermoscopy given by dermatologists working in individual private practices and public healthcare facilities was the lack of equipment (Fig. S1; see Supporting Information).

\section{Factors related to high use of dermoscopy}

Almost two-thirds of all dermoscopy users (62\%) were also 'high users' of dermoscopy (as defined above). In the univariate analysis (Tables 2 and 3), high use of dermoscopy was significantly associated with slightly lower age and shorter duration of dermatology specialist practice, working in individual private practice, a higher number of patients with skin 
cancer seen per month, having received dermoscopy training during residency, and having received any type of dermoscopy training. Dermatologists reporting high use of dermoscopy were more likely to report the use of polarized light devices or digital dermoscopy devices compared with low users of dermoscopy, and were more likely to use pattern analysis or no predefined dermoscopic algorithm. High use was also associated with a longer duration of dermoscopy practice, with positive views on dermoscopy and with higher confidence in diagnostic skills across all categories of skin lesions (Table S1; see Supporting Information).

The overall number of patients seen or the use of contact immersion dermoscopy did not differ significantly between high and low users of dermoscopy. Working in public hospitals (except university hospitals) was associated with lower use of dermoscopy.

For both high and low users of dermoscopy, the education methods most frequently reported outside residency training were books and atlases ( $83 \%$ and $76 \%$, respectively), followed by attending conferences and formal dermoscopy courses. A smaller proportion of high and low users (26\% and 19\%, respectively) benefited from having a mentor or tutor teaching, and up to one-fifth took advantage of online courses.

In the multivariate analysis, high use of dermoscopy remained significantly associated with female gender, having received online dermoscopy training, using polarized light and digital video-dermoscopy systems, longer practice, with using pattern analysis but not the ABCD rule (Tables 2 and 3) and also with a positive opinion about the benefits of dermoscopy and self-confidence in their dermoscopic diagnosis skills required for detecting nonpigmented skin tumours (Table S1; see Supporting Information).

\section{Discussion}

This study is the first pan-European analysis of the patterns of dermoscopy use by dermatologists. With 7500 responses, representing one in every five dermatologists registered in 32 European countries, this is the largest survey to date and it offers a unique view of the factors modulating the use of this technique across the continent. Thus, it provides a valuable knowledge base for future strategies to enhance the use of dermoscopy towards achieving improved diagnosis of skin diseases and early detection of skin cancers in Europe.

While recognizing the limitations of a lack of response from many European dermatologists, our study suggests that dermoscopy is well-established in dermatology practice across Europe. Still, $11 \%$ of participating dermatologists do not use dermoscopy, a proportion higher than that previously reported. ${ }^{4,5}$ Notably, the main reasons for not using dermoscopy include the lack of education and equipment, but not the lack of time, interest for the technique or financial

Table 2 Demographic and practice setting factors associated with high use of dermoscopy

\begin{tabular}{|c|c|c|c|c|}
\hline & $\begin{array}{l}\text { High dermoscopy } \\
\text { users }\end{array}$ & $\begin{array}{l}\text { Low dermoscopy } \\
\text { users }\end{array}$ & P-value & $\begin{array}{l}\text { P-value } \\
\text { multivariate }^{a}\end{array}$ \\
\hline$N=6118$ & $3830(62 \cdot 60)$ & $2288(37 \cdot 40)$ & & \\
\hline Female participants & $2594(68 \cdot 07)$ & $1487(65 \cdot 28)$ & $0 \cdot 162$ & 0.016 \\
\hline Age, years, mean (SD) & $46 \cdot 3(10 \cdot 74)$ & 48.09 (SD: 11.32) & $<0.001$ & \\
\hline \multicolumn{5}{|l|}{ Place of work } \\
\hline Individual private practice & $1606(41.93)$ & $750(32 \cdot 78)$ & $<0.001$ & \\
\hline Private ambulatory/hospital & $722(18 \cdot 85)$ & $488(21 \cdot 33)$ & $0 \cdot 142$ & \\
\hline Public ambulatory/hospital & $1092(28 \cdot 51)$ & $766(33 \cdot 48)$ & $<0.001$ & \\
\hline University hospital & $819(21 \cdot 38)$ & $495(21 \cdot 63)$ & 1.000 & \\
\hline $\begin{array}{l}\text { Involved in teaching activity for } \\
\text { dermatology residents }\end{array}$ & $502(13 \cdot 11)$ & $290(12 \cdot 67)$ & $1 \cdot 000$ & \\
\hline $\begin{array}{l}\text { Years as dermatology specialist, } \\
\text { mean (SD) }\end{array}$ & $15 \cdot 39(10 \cdot 49)$ & $17 \cdot 42(10 \cdot 95)$ & $<0.001$ & \\
\hline $\begin{array}{l}\text { No. of patients seen per month, } \\
\text { mean (SD) }\end{array}$ & $444 \cdot 86(395 \cdot 28)$ & $427 \cdot 18(420 \cdot 72)$ & $0 \cdot 428$ & \\
\hline $\begin{array}{l}\text { No. of patients with skin cancer } \\
\text { seen per month, mean (SD) }\end{array}$ & $66 \cdot 74(117 \cdot 87)$ & $49 \cdot 25(92 \cdot 55)$ & $<0.001$ & 0.033 \\
\hline Dermoscopy training during residency & $1727(45 \cdot 63)$ & $810(35 \cdot 89)$ & $<0.001$ & \\
\hline \multicolumn{5}{|l|}{ Types of nonresidency dermoscopy training } \\
\hline Dermoscopy course & $2581(67 \cdot 39)$ & $1323(57 \cdot 82)$ & $<0.001$ & \\
\hline Online dermoscopy course & $809(21 \cdot 12)$ & $326(14 \cdot 25)$ & $<0.001$ & 0.025 \\
\hline Attended conferences congresses & $2901(75 \cdot 74)$ & $1533(67 \cdot 00)$ & $<0.001$ & \\
\hline Books and atlases & $3186(83 \cdot 19)$ & $1753(76 \cdot 62)$ & $<0.001$ & \\
\hline Mentor tutor & $1003(26 \cdot 19)$ & $431(18 \cdot 84)$ & $<0.001$ & \\
\hline No training & $97(2.53)$ & $100(4 \cdot 37)$ & 0.001 & \\
\hline
\end{tabular}

${ }^{a}$ Variables without a P-value in this column were not significant in multivariate analysis and were not entered into the model as they did not improve the regression model. Continuous data are given as mean with $\mathrm{SD}$, proportions as $\mathrm{n}(\%)$. 
Table 3 Practice factors associated with high use of dermoscopy

\begin{tabular}{|c|c|c|c|c|}
\hline & $\begin{array}{l}\text { High dermoscopy } \\
\text { users }\end{array}$ & $\begin{array}{l}\text { Low dermoscopy } \\
\text { users }\end{array}$ & P-value & $\begin{array}{l}\text { P-value } \\
\text { multivariate }^{\mathrm{a}}\end{array}$ \\
\hline$N=6118$ & $3830(62 \cdot 60)$ & $2288(37 \cdot 40)$ & & \\
\hline \multicolumn{5}{|l|}{ No. of years using dermoscopy ${ }^{b}$} \\
\hline$<2$ years & $284(7 \cdot 45)$ & $360(15 \cdot 80)$ & $<0.001$ & $<0.001$ \\
\hline $2-5$ years & $710(18 \cdot 63)$ & $506(22 \cdot 20)$ & & \\
\hline$>5$ years & $2818(73 \cdot 92)$ & $1413(62 \cdot 00)$ & & \\
\hline \multicolumn{5}{|l|}{ Types of dermoscopes used } \\
\hline Nonpolarized immersion contact & $2025(52 \cdot 87)$ & $1266(55 \cdot 33)$ & $0 \cdot 328$ & \\
\hline Polarized light dermoscope & $2223(58 \cdot 04)$ & $1050(45 \cdot 89)$ & $<0.001$ & $0 \cdot 021$ \\
\hline Dermoscope with digital camera & $961(25 \cdot 09)$ & $422(18 \cdot 44)$ & $<0.001$ & \\
\hline Digital videodermatoscopy system & $1174(30 \cdot 65)$ & $424(18 \cdot 53)$ & $<0.001$ & $0 \cdot 012$ \\
\hline \multicolumn{5}{|l|}{ Average frequency of using dermoscopy ${ }^{b}$} \\
\hline Less than once per month & $10(0 \cdot 26)$ & $37(1.62)$ & $<0.001$ & $<0.001$ \\
\hline $1-4$ times per month & $62(1.62)$ & $185(8 \cdot 10)$ & & \\
\hline More than once per week & $244(6 \cdot 39)$ & $406(17 \cdot 78)$ & & \\
\hline Daily & $3501(91 \cdot 72)$ & $1655(72 \cdot 49)$ & & \\
\hline Regularly used dermoscopic algorithm & & & 0.597 & \\
\hline $\mathrm{ABCD}$ rule & $1018(26 \cdot 58)$ & $841(36 \cdot 76)$ & $<0.001$ & $0 \cdot 001$ \\
\hline $\mathrm{CASH}$ & $22(0 \cdot 57)$ & $17(0 \cdot 74)$ & $1 \cdot 000$ & \\
\hline Menzies algorithm & $107(2 \cdot 79)$ & $51(2 \cdot 23)$ & $0 \cdot 825$ & \\
\hline Seven-point check list & $331(8 \cdot 64)$ & $155(6 \cdot 77)$ & $0 \cdot 093$ & \\
\hline Pattern analysis & $1338(34.93)$ & $522(22 \cdot 81)$ & $<0.001$ & $<0.001$ \\
\hline I do not systematically use any particular algorithm & $1057(27 \cdot 60)$ & $721(31 \cdot 51)$ & $0 \cdot 012$ & \\
\hline
\end{tabular}

CASH: Colour, Architecture, Symmetry and Homogeneity. ${ }^{a}$ Variables without a P-value in this column were not significant in multivariate analysis and were not entered into the model as they did not improve the regression model. ${ }^{\text {V}}$ Variables with a calculated linear correlation in multivariate analysis.

incentives. This is in sharp contrast with other reports ${ }^{4,5,8}$ and is based on a significantly large sample, suggesting that improving education and access to equipment could enhance the use of dermoscopy by European dermatologists.

The importance of education for enhancing the use of dermoscopy was a main finding of our study, confirming the insights from previous national reports on a pan-European scale. ${ }^{4,5,8,10}$ Half of dermatologists who did not use dermoscopy had not received any training in dermoscopy, and a lack of training and confidence in their own dermoscopy skills were among the main reasons for not using dermoscopy. Access to dermoscopy education was also an important factor associated with high use of dermoscopy compared with low use. Residency dermoscopy training appeared to be particularly important in distinguishing dermoscopy users vs. nonusers and high users vs. low users. As less than $40 \%$ of all respondents reported dermoscopy training during residency, this is an area where improvement is needed towards achieving a harmonized, high-standard education of dermatologists across Europe in order to comply with current practice guidelines, ${ }^{29-32}$ where dermoscopy becomes the standard of care.

Practice setting was another noteworthy factor influencing the use of dermoscopy in Europe. Both nonusers and low users of dermoscopy were more likely to work in public healthcare facilities than in other settings. In contrast, dermatologists working in individual practices were the most likely to use dermoscopy. The reasons for these differences require further exploration. The lack of available equipment may play a role, as this was a common reason given by physicians who did not use dermoscopy and worked in public healthcare facilities. A lack of training or workload, as reasons for not using dermoscopy, did not appear to differ between private or public practice settings $(P=0 \cdot 154)$. Overall, dermoscopy users reported a much higher number of patients seen per month than nonusers (Table 1), and there was no significant difference between the number of patients seen monthly by high users vs. low users.

Dermoscopy users in general, and high users in particular, saw more patients with skin cancer per month and were most confident in their diagnostic skills for pigmented skin tumours. This suggests that the main use of dermoscopy remains related to the diagnosis of melanoma and skin cancers. At the other end of the spectrum, inflammatory lesions (for which dermoscopy use is still under exploration and standardization $)^{27,28}$ was the category in which dermoscopy was used least often, its benefits were perceived to be lower and the lowest self-confidence was expressed by a considerable proportion of responders.

Many algorithms exist to facilitate the dermoscopic diagnosis of skin lesions, particularly for melanoma. ${ }^{38-40}$ In our study, it was interesting to find that use of the classic $A B C D$ algorithm was reported mostly by low users of dermoscopy $(37 \%)$, while pattern analysis was favoured by high users (35\%). Roughly one-third of respondents in both high-use and low-use categories reported not using any algorithm in particular. 
Contact immersion dermoscopy and polarized light dermoscopy appeared to be used with equal frequency by European dermatologists, and about $37 \%$ of responders reported using a digital dermoscopy device. As digital photo or videodermoscopy systems are essential for monitoring melanocytic lesions and monitoring patients with a risk of melanoma, ${ }^{17,41-43}$ these results suggest that a minority of dermatologists who use dermoscopy are equipped for the proper management of skin cancer and high-risk patients.

The demographics of our respondents were comparable with similar surveys, with a majority of female responders, likely reflecting the higher proportion of female physicians in dermatology practice worldwide. The mean age of our responders across Europe was lower than reported in France and the U.K., ${ }^{4,5}$ and dermoscopy use was not associated with younger age in our study, likely reflecting the heterogeneity in the age distribution and training of dermatologists among European countries.

Our study has several limitations inherent to its design and proportions. The representativeness and possible selection bias are issues common to all similar studies. We chose to report the number of responders relative to the total number of dermatologists officially registered in the participating countries, and not to the number of dermatologists contacted, in order to have a reliable parameter for assessing the penetrance and representativeness of our survey. As the inclusion of dermatologists in different professional associations or contact databases varied significantly among countries, we considered that the official number of dermatologists issued by the health authority is a more informative denominator for our analysis. Using this definition, we reached a median response rate of $33 \%$ of all dermatologists in the participating countries. Similar studies on a national scale had a response rate of $22 \%$ of British Association of Dermatologists ${ }^{4}$ and $49 \cdot 6 \%$ of all registered private dermatologists in France. ${ }^{5}$ Obtaining more than 8000 surveys reflects not only the interest that European dermatologists have in dermoscopy, but also the strong commitment of the NCTs to reach and motivate the responders, and the effectiveness of the methodology.

It may be argued that a survey of this type is more likely to be answered by dermoscopy users than nonusers or frequent users of dermoscopy rather than sporadic users. Nonetheless, we received surveys from more than 800 nonusers and many more sporadic users. Our analysis takes the pan-European view, as mobility of patients, physicians and trainees, coupled with the common historical and political framework, unites European countries in facing common challenges in medical care. Thus, a common vision and a harmonized strategy are needed. However, there are notable differences in health system organization and training for dermatologists among European and even EU countries, which will require tailored solutions. While it is difficult to make comparisons between individual countries because of the different response rates, a more detailed analysis of our results regarding regional patterns is ongoing and will be reported in the future.
The survey was addressed to dermatologists, as they are the main users of dermoscopy across all European countries. While the extension of dermoscopy training to general practitioners or specialized nurses is considered by some countries, $^{44}$ this practice is still nascent in most parts of the European continent and could be considered for future research.

In conclusion, owing to its large size and pan-European reach, this study allows for an unprecedented view of dermoscopy practice across the continent. Among up to 7500 respondents, dermoscopy appears to be a well-established diagnostic method, widely used and well regarded by European dermatologists. Expanding access to the relatively inexpensive equipment, especially in public healthcare facilities and establishing dermoscopy training as a key part of dermatology residency appear to be the main pathways, which are both feasible and affordable, to enhance the use of this technique across European countries. In light of the rich evidencebased benefits of dermoscopy for the early detection of skin cancers and the noninvasive diagnosis of skin diseases, this in turn might have far-reaching benefits for improving the landscape of dermatological care in Europe.

\section{Acknowledgments}

The authors would like thank Gerald Gabler, IDS webmaster, who accomplished the essential tasks of creating the study webpage, setting up and maintaining the online survey for 32 participating countries, creating the central online study database and for participating in the data cleaning. The authors would also like to thank all the members of NCTs for their efforts in translating the questionnaires, disseminating the survey, motivating the dermatologists to respond and collecting offline answers. Their names are listed on the Eurodermoscopy website http://euro.dermoscopy-ids.org.

\section{References}

1 Argenziano G, Albertini G, Castagnetti F et al. Early diagnosis of melanoma: what is the impact of dermoscopy? Dermatol Ther 2012; 25:403-9.

2 Argenziano G, Giacomel J, Zalaudek I et al. A clinico-dermoscopic approach for skin cancer screening: recommendations involving a survey of the International Dermoscopy Society. Dermatol Clin 2013; 31:525-34, vii.

3 Breton AL, Amini-Adle M, Duru G et al. Overview of the use of dermoscopy in academic and non-academic hospital centres in France: a nationwide survey. J Eur Acad Dermatol Venereol 2014; 28: 1207-13.

4 Butler TD, Matin RN, Affleck AG et al. Trends in dermoscopy use in the UK: results from surveys in 2003 and 2012. Dermatol Pract Concept 2015; 5:29-38.

5 Moulin C, Poulalhon N, Duru G et al. Dermoscopy use by French private practice dermatologists: a nationwide survey. Br J Dermatol 2013; 168:74-9.

6 Piliouras P, Buettner P, Soyer HP. Dermoscopy use in the next generation: a survey of Australian dermatology trainees. Australas J Dermatol 2014; 55:49-52. 
7 Venugopal SS, Soyer HP, Menzies SW. Results of a nationwide dermoscopy survey investigating the prevalence, advantages and disadvantages of dermoscopy use among Australian dermatologists. Australas J Dermatol 2011; 52:14-18.

8 Engasser HC, Warshaw EM. Dermatoscopy use by US dermatologists: a cross-sectional survey. J Am Acad Dermatol 2010; 63:412-19, 419.e1-2.

9 Murzaku EC, Hayan S, Rao BK. Methods and rates of dermoscopy usage: a cross-sectional survey of US dermatologists stratified by years in practice. J Am Acad Dermatol 2014; 71:393-5.

10 Noor O 2nd, Nanda A, Rao BK. A dermoscopy survey to assess who is using it and why it is or is not being used. Int J Dermatol 2009; 48:951-2.

11 Terushkin V, Oliveria SA, Marghoob AA, Halpern AC. Use of and beliefs about total body photography and dermatoscopy among US dermatology training programs: an update. J Am Acad Dermatol 2010; 62:794-803.

12 Forsea AM, Del Marmol V, de Vries E et al. Melanoma incidence and mortality in Europe: new estimates, persistent disparities. Br J Dermatol 2012; 167:1124-30.

13 Arnold M, Holterhues C, Hollestein LM et al. Trends in incidence and predictions of cutaneous melanoma across Europe up to 2015. J Eur Acad Dermatol Venereol 2014; 28:1170-8.

14 Barbaric J, Sekerija M, Agius D et al. Disparities in melanoma incidence and mortality in South-Eastern Europe: increasing incidence and divergent mortality patterns. Is progress around the corner? Eur J Cancer 2016; 55:47-55.

15 De Angelis R, Sant M, Coleman MP et al. Cancer survival in Europe 1999-2007 by country and age: results of EUROCARE-5-a population-based study. Lancet Oncol 2014; 15:23-34.

16 de Vries E, Coebergh JW. Cutaneous malignant melanoma in Europe. Eur J Cancer 2004; 40:2355-66.

17 Argenziano G, Cerroni L, Zalaudek I et al. Accuracy in melanoma detection: a 10-year multicenter survey. J Am Acad Dermatol 2012; 67:54-9.

18 Kittler H, Pehamberger H, Wolff K, Binder M. Diagnostic accuracy of dermoscopy. Lancet Oncol 2002; 3:159-65.

19 Liebman TN, Goulart JM, Soriano R et al. Effect of dermoscopy education on the ability of medical students to detect skin cancer. Arch Dermatol 2012; 148:1016-22.

20 Tromme I, Devleesschauwer B, Beutels P et al. Selective use of sequential digital dermoscopy imaging allows a cost reduction in the melanoma detection process: a Belgian study of patients with a single or a small number of atypical nevi. PLoS ONE 2014; 9: e109339.

21 Tromme I, Sacré L, Hammouch F et al. Availability of digital dermoscopy in daily practice dramatically reduces the number of excised melanocytic lesions: results from an observational study. $\mathrm{Br}$ J Dermatol 2012; 167:778-86.

22 van der Rhee JI, Bergman W, Kukutsch NA. The impact of dermoscopy on the management of pigmented lesions in everyday clinical practice of general dermatologists: a prospective study. Br J Dermatol 2010; 162:563-7.

23 Vestergaard ME, Macaskill P, Holt PE, Menzies SW. Dermoscopy compared with naked eye examination for the diagnosis of primary melanoma: a meta-analysis of studies performed in a clinical setting. Br J Dermatol 2008; 159:669-76.

24 Zalaudek I, Kreusch J, Giacomel J et al. How to diagnose nonpigmented skin tumors: a review of vascular structures seen with dermoscopy: part II. Nonmelanocytic skin tumors. J Am Acad Dermatol 2010; 63:377-86; quiz 87-8.

25 Zalaudek I, Kreusch J, Giacomel J et al. How to diagnose nonpigmented skin tumors: a review of vascular structures seen with dermoscopy: part I. Melanocytic skin tumors. J Am Acad Dermatol 2010; 63:361-74.

26 Giacomel J, Zalaudek I, Argenziano G, Lallas A. Dermoscopy of hypertrophic lupus erythematosus and differentiation from squamous cell carcinoma. J Am Acad Dermatol 2015; 72(1 Suppl.):S33-6.

27 Errichetti E, Stinco G. The practical usefulness of dermoscopy in general dermatology. G Ital Dermatol Venereol 2015; 150:533-46.

28 Goncharova Y, Attia EA, Souid K et al. Dermoscopic features of clinically inflammatory dermatoses and their correlation with histopathologic reaction patterns. Arch Dermatol Res 2015; 307:2330 .

29 Garbe C, Peris K, Hauschild A et al. Diagnosis and treatment of melanoma. European consensus-based interdisciplinary guidelineupdate 2012. Eur J Cancer 2012; 48:2375-90.

30 Pflugfelder A, Kochs C, Blum A et al. Malignant melanoma S3guideline 'diagnosis, therapy and follow-up of melanoma'. J Dtsch Dermatol Ges 2013; 11(Suppl. 6):1-116, 1-26.

31 Watts CG, Dieng M, Morton RL et al. Clinical practice guidelines for identification, screening and follow-up of individuals at high risk of primary cutaneous melanoma: a systematic review. Br J Dermatol 2015; 172:33-47.

32 Marsden JR, Newton-Bishop JA, Burrows L et al. Revised U.K. guidelines for the management of cutaneous melanoma 2010. Br J Dermatol 2010; 163:238-56.

33 United Nations Statistics Division. Composition of macro geographical (continental) regions, geographical sub-regions, and selected economic and other groupings. Available at http://unstats.un.org/unsd/methods/m49/m49regin.htm\#europe (last accessed 27 September 2016).

34 Stratigos AJ, Forsea AM, van der Leest RJ et al. Euromelanoma: a dermatology-led European campaign against nonmelanoma skin cancer and cutaneous melanoma. Past, present and future. Br J Dermatol 2012; 167 (Suppl. 2):99-104.

35 Council of Europe. 47 Member States. Available at: http://www.coe.int/en/web/portal/47-members-states (last accessed on 27 September 2016).

36 Holm S. A simple sequentially rejective multiple test procedure. Scand J Stat 1979; 6:65-70.

37 Wickham H. ggplot2: Elegant Graphics for Data Analysis. New York: Springer-Verlag, 2009.

38 Argenziano G, Soyer HP, Chimenti S et al. Dermoscopy of pigmented skin lesions: results of a consensus meeting via the Internet. J Am Acad Dermatol 2003; 48:679-93.

39 di Meo N, Stinco G, Bonin S et al. CASH algorithm versus 3-point checklist and its modified version in evaluation of melanocytic pigmented skin lesions: the 4-point checklist. J Dermatol 2016; 43:682-5.

40 Scope A, Braun RP. The recognition process in dermoscopy: analytic approach vs heuristic approach. JAMA Dermatol 2015; 151:704-6.

41 Moloney FJ, Guitera P, Coates E et al. Detection of primary melanoma in individuals at extreme high risk: a prospective 5-year follow-up study. JAMA Dermatol 2014; 150:819-27.

42 Moscarella E, Pampena R, Kyrgidis A et al. Digital dermoscopy monitoring in patients with multiple nevi: How many lesions should we monitor per patient? J Am Acad Dermatol 2015; 73:168-70.

43 Leachman SA, Cassidy PB, Chen SC et al. Methods of melanoma detection. Cancer Treat Res 2016; 167:51-105.

44 Koelink CJ, Vermeulen KM, Kollen BJ et al. Diagnostic accuracy and cost-effectiveness of dermoscopy in primary care: a cluster randomized clinical trial. J Eur Acad Dermatol Venereol 2014; 28: 1442-9. 


\section{Appendix 1}

\section{Eurodermoscopy Working Group}

M. Arenbergerova (Department of Dermatology, Third Medical Faculty, Charles University Prague, Czech Republic), A. Azenha (Hospital Privado da Trofa, Trofa, Portugal), A. Blum (DermPrevOncol, Public, Private and Teaching Practice of Dermatology, Konstanz, Germany), J.C. Bowling (Private Practice, Nuffield Hospital, Oxford, U.K.), R.P. Braun (Department of Dermatology, University Hospital of Zürich, Zürich, Switzerland), M. Bylaite-Bucinskiene (Centre of Dermatovenereology, Vilnius University, Vilnius, Lithuania), L. Čabrijan (Department of Dermatovenereology, Clinical Hospital Center Rijeka, Rijeka, Croatia), H. Dobrev (Department of Dermatology and Venereology, Medical Faculty, Medical University, Plovdiv, Bulgaria), J. Hegy (Institute of Clinical and Experimental Dermatovenereology, Bratislava, Slovakia), H. Helppikangas (Dermatology Department, Clinical Center, University of Sarajevo, Sarajevo, Bosnia \& Herzegovina), R. Hofmann-Wellenhof (Department of Dermatology, Medical University Graz, Graz, Austria), R. Karls (Department of Infectology and Dermatology, Riga Stradins University, Derma Clinic Riga, Riga, Latvia), U. Krumkachou (Dermatovenereology and Cosmetology Department, Belarusian Medical Academy of Post-Graduate Education, Minsk, Belarus), N. Kukutsch (Department of Dermatology, Leiden University Medical Center, Leiden, the Netherlands), I. McCormack (Belfast Health \& Social Care Trust, Belfast, U.K.), L. Mekokishvili (Dermatovenereology Department at Petre Shotadze Tbilisi Medical Academy, Tbilisi, Georgia), N. Nathansohn (Department of Dermatology and the Advanced Technologies Center, C. Sheba Medical Center, Tel Hashomer, Israel), K. Nielsen (Lund University, Helsingborg Hospital, Department of Clinical Sciences Lund, Dermatology and Venereology, Lund, Sweden), J. Olah (Department of Dermatology and Allergology, University of Szeged, Szeged,
Hungary), F. Özdemir (Dermato-Oncology Unit, Department of Dermatology, Ege University, Medical Faculty, Izmir, Turkey), S. Puig [Melanoma Unit, Dermatology Department, Hospital Clínic \& IDIBAPS (Institut d’Investigacions Biomèdiques August Pi i Sunyer), Barcelona, Spain; Centro Investigación Biomédica en Red de Enfermedades Raras (CIBERER), Instituto de Salud Carlos III (ISCIII), Barcelona, Spain and Departament de Medicina, Universitat de Barcelona, Barcelona, Spain.], P. Rubegni (Department of Medical and Surgical Science and Neuroscience, University of Siena, Siena, Italy), T. Planinsek Rucigaj (Dermatovenereological Clinic, University Medical Centre Ljubljana, Ljubljana, Slovenia), T.R. Schopf (Norwegian Centre for E-health Research, University Hospital of North-Norway, Tromsø, Norway), V. Sergeev (Central Research Dermatology Clinic, Moscow, Russia), A. Stratigos (First Department of Dermatology-Venereology, National and Kapodistrian University of Athens School of Medicine, Andreas Sygros Hospital, Athens, Greece), L. Thomas (Lyon 1 University, Lyon, France; Dermatology Centre Hospitalier Lyon Sud, Lyon, France and Lyon Cancer Research Center INSERM U1052 - CNRS UMR5286, Lyon, France), D. Tiodorovic (Clinic of Dermatovenereolgy, Clinical Center of Nis, Medical Faculty, Nis, Serbia), A. Vahlberg (Vahlberg \& Pild Ltd., Tallinn, Estonia) and Z. Zafirovik (University Clinic of Dermatology, Medical Faculty, University 'St. Cyril and Methodius', Skopje, the former Yugoslav Republic of Macedonia).

\section{Supporting Information}

Additional Supporting Information may be found in the online version of this article at the publisher's website:

Appendix S1. Eurodermoscopy questionnaire.

Fig S1. Reasons for not using dermoscopy by work setting.

Table S1. Attitudes related to high use of dermoscopy. 